\title{
Estrous Cycle Based on Blood Progesterone Profiles and Changes in Vulvar Appearance of Malayan Tapirs (Tapirus indicus)
}

\author{
Satoshi KUSUDA ${ }^{1)}$, Masakazu IKOMA ${ }^{2)}$, Koki MORIKAKU ${ }^{3)}$, \\ Jun-ichi KOIZUMI ${ }^{3)}$, Yoshiya KAWAGUCHI ${ }^{4)}$, Kuniyasu KOBAYASHI ${ }^{4)}$, \\ Kirito MATSUI ${ }^{4)}$, Akira NAKAMURA ${ }^{5)}$, Hisashi HASHIKAWA ${ }^{5)}$, \\ Kazuhiro KOBAYASHI ${ }^{2) \# \#, ~ M i y a ~ U E D A ~}{ }^{4)}$, Mikako KANEKO ${ }^{2)}$, \\ Takako AKIKAWA ${ }^{2)}$, Sachiko SHIBAGAKI ${ }^{1)}$ and Osamu DOI ${ }^{1)}$
}

${ }^{1)}$ Faculty of Applied Biological Sciences, Gifu University, Gifu 501-1193, ${ }^{2)}$ Tama Zoological Park, Tokyo 191-0042, ${ }^{3)}$ Preservation and Research Center, City of Yokohama, Yokohama 241-0804, ${ }^{4)}$ Yokohama Zoological Gardens ZOORASIA, Yokohama 241-0001 and ${ }^{5}$ Nagoya Higashiyama Zoo, Nagoya 464-0804, Japan

"Present: Kanazawa Zoological Gardens of Yokohama, Kanagawa 236-0042 and

\#\#Present: Shibaura Meat Sanitary Inspection Station, Tokyo 108-0075, Japan

\begin{abstract}
The progesterone $\left(\mathrm{P}_{4}\right)$ profiles and macroscopic vulvar changes of female Malayan tapirs were investigated in order to understand their fundamental reproductive physiology and to search for visual indicators of estrus. Blood was collected once or twice a week from seven female Malayan tapirs kept at four zoos. Serum or plasma $\mathrm{P}_{4}$ concentrations were determined by radioimmunoassay. The $\mathrm{P}_{4}$ concentrations changed cyclically throughout the years, and a total of 56 cycles was confirmed in the seven females. The length of the estrous cycle based on the $\mathrm{P}_{4}$ profiles was $43.6 \pm 2.0$ days; however, this mean includes great variation in length, from 21 to 84 days. Mucous discharge from the vulva and vulvar swelling were seen when the $\mathrm{P}_{4}$ concentrations were low before the beginning of a rise in most cases. In conclusion, captive female Malayan tapirs have variations of approximately 1 to 3 months in estrous cycle length, and visual changes in the vulva are helpful in estimating estrus in female Malayan tapirs.
\end{abstract}

Key words: Estrous cycle, Malayan tapir (Tapirus indicus), Mucus, Progesterone, Vulva

(J. Reprod. Dev. 53: 1283-1289, 2007)

$\mathbf{T}$ he family Tapiridae consists of 1 genus and 4 species including the Malayan tapir (Tapirus indicus), Brazilian/lowland tapir (T. terrestris), Baird's tapir (T. bairdii) and Mountain/Woolly tapir (T. pinchaque) [1-3]. According to the 2006 IUCN Red List of Threatened Species, Malayan tapirs are classified as Vulnerable and are considered to be

Accepted for publication: September 14, 2007

Published online: October 23, 2007

Correspondence: O. Doi (e-mail: doi@gifu-u.ac.jp) facing a high risk of extinction [4]. The major reasons for decrease of wild population are poaching for hides and medicine and a decrease in habitats and food resources resulting from deforestation due to farmland expansion $[3,5]$.

There has been a long history of keeping Tapirs in zoological gardens. The Malayan tapir was first exhibited in the London Zoo in 1840, and there is a old record of a birth at the Hamburg Zoo in 1879 [6]. Despite the long history and successful breed- 
Table 1. Individual information for the female Malayan tapirs investigated in this study

\begin{tabular}{llllll}
\hline $\begin{array}{l}\text { Individual } \\
\text { No. }\end{array}$ & Name & Age $^{3)}$ & Birth history & Facility ${ }^{6)}$ & Period of blood sampling \\
\hline$\# 14^{2)}$ & Yumeko & 23 & Uniparous & TZP & Sep 3-Dec 20, 2003 \\
$\# 44$ & Koro & 12 & Nulliparous & TZP & Sep 24, 2001-Dec 13, 2003 \\
$\# 56$ & Ume & 9 & Nulliparous & PRC & Mar 7-May 25, 2001 \\
$\# 60$ & Mimi & 8 & Nulliparous ${ }^{5)}$ & YZG & Jul 23-Oct 29, 2001 \\
$\# 61$ & Maya & 5 & Nulliparous ${ }^{5)}$ & YZG & Sep 23, 2001-Apr 23, 2004 \\
$\# 62$ & Takeko & $2^{4)}$ & Nulliparous & PRC & Jan 13, 2000-Jun 23, 2004 \\
$\# 86$ & Sachiko & 2 & Nulliparous & NHZ & Jan 14, 2005-Feb 19, 2006 \\
\hline
\end{tabular}

1) Japanese Studbook of Tapir. ${ }^{2)}$ Died as a result of decrepitude at 23 years of age (December 21, 2003). ${ }^{3)}$ At the beginning of study. ${ }^{4)}$ Estimated. ${ }^{5)}$ Successful breeding after this study period. ${ }^{6)}$ TZP: Tama Zoological Park; PRC: Preservation and Research Center, City of Yokohama; YZG: Yokohama Zoological Gardens ZOORASIA, Japan.

ing in captivity, the current status of Malayan tapirs in captivity is not good. As of April 2006, a total of 154 Malayan tapirs are registered at International Species Information System (ISIS) registration facilities [7]. However, there has been a trend towards a decrease in the number of captive populations in recent years. According to the Japanese Studbook of Tapirs [8], 29 Malayan tapirs are kept at 9 zoological institutes in Japan (December 31, 2004), the number of births from 1999 to 2004 was approximately one per year and the number of deaths was one or more per year. To maintain the Japanese captive population is proving difficult at present, because the numbers of parous females and pairs showing copulation behavior are limited. Recently, with the goal of improving captive breeding in Japanese zoos, females were housed together with a male only during estrus in consideration of their lifestyle, which in the wild is solitary except during estrus. Therefore, it is important to determine when females are in estrus. It has been reported that the estrous cycles of all 4 species in captivity are approximately one month in length $[1,5]$. These cycle lengths have been presumed based on the interval of courtship and/or copulatory behaviors. If neither courtship nor copulation is observed, it is difficult to detect estrus in the female [9].

There are limited reports concerning the endocrinology of the estrous cycle in tapirs. In Baird's tapirs, longitudinal profiles of serum progesterone $\left(\mathrm{P}_{4}\right)$ and estradiol have been investigated during the estrous cycles and pregnancy [10], and the estrous cycle in Brazilian tapirs has been determined based on plasma $\mathrm{P}_{4}$ profiles [12]. Only recently, a short communication was published concerning the estrous cycle of one Malayan tapir based on the profiles of plasma $\mathrm{P}_{4}$ and estradiol [13]. Only three reports seem to be available concerning the endocrinological estrous cycle of tapirs.

In the present study, the longitudinal profiles of the blood serum/plasma $\mathrm{P}_{4}$ concentrations were monitored to understand the fundamental reproductive physiology, in particular the estrous cycle, of the Malayan tapir. In addition, the relationship between $\mathrm{P}_{4}$ profiles and macroscopic vulvar changes was investigated to determine the utility of vulvar observation as a visual indicator of estrus.

\section{Materials and Methods}

\section{Animals and management}

A total of seven female Malayan tapirs kept at the Tama Zoological Park (TZP), Yokohama Zoological Gardens (YZG), Preservation and Research Center, City of Yokohama (PRC), and Nagoya Higashiyama Zoo (NHZ), Japan, were studied for a period of 3 months to 4.5 years (Table 1). The animals were fed a daily diet of timothy or alfalfa hay, fresh grass, branches and leaves, pellets, sweet potato, carrots, apples and other components (bananas, cabbages and/or sliced bread). Drinking water was available ad libitum. Female \#44 was housed with a male from September 13, 2002 to December 7, 2003 and on a few other days; female \#61 was housed with a male from February 1, 2002 to February 23, 2004 and on a few other days. Female \#62 were weighed weekly or monthly since she was new to the PRC. 


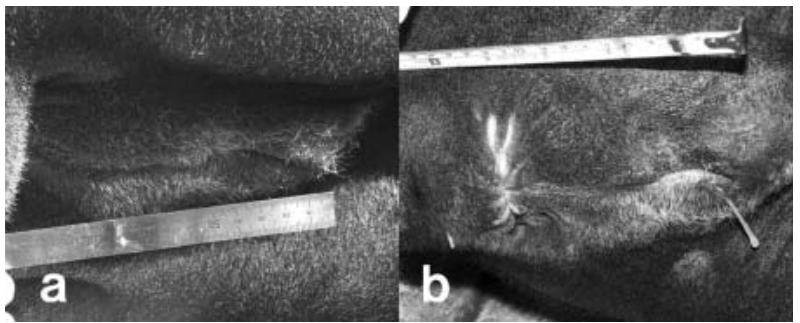

Fig. 1. Vulvar appearance of female Malayan tapir \#44. (a) Score 0: normal vulva (April 6, 2002). (b) Score 1: mucous discharge from the vulva and vulvar swelling (March 2, 2002).

\section{Blood collection}

Operant conditioning techniques [14] were used to collect blood from the seven tapirs for several months prior to regular blood collection. All of the tapirs responded to the training and learned to lie down or to sleep in a lateral position in response to being brushed and massaged [15]. Blood was collected once or twice a week. When each tapir was encouraged to take the lateral recumbent posture by body brushing and massage, blood sampling was performed from a cephalic vein of the forelimb or a medial saphenous vein of the hindlimb without physical or chemical restraint. Sera from females \#14, \#44, \#60, \#61 and \#86 (TZP, YZG, NHZ) and plasma from females \#56 and \#62 (PRC) were separated from whole blood and stored at -30 C until assay.

\section{Radioimmunoassay}

Serum or plasma $\mathrm{P}_{4}$ was extracted with diethyl ether, and the level was determined by radioimmunoassay as described previously [16, 17]. More than $97 \%$ of $\mathrm{P}_{4}$ was recovered after the extraction. The cross-reactivity of the antiserum used in this assay was $100 \%$ for $\mathrm{P}_{4}, 62.2 \%$ for $5 \alpha$-pregnanedione, $6.26 \%$ for pregnenolone, $3.88 \%$ for 11 deoxycorticosterone, $2.25 \%$ for $17 \alpha$-hydroxyprogesterone and $1.23 \%$ for $11 \alpha$-hydroxyprogesterone. Assay sensitivity based on the lower limit of the assay was $<30 \mathrm{pg} / \mathrm{ml}$. The intra- and interassay coefficients of variation were 7.9 and $16.2 \%$, respectively.

\section{Observation of vulvar appearance}

Mucous discharge from the vulva and vulvar swelling of two females, \#44 and \#61, were observed and recorded visually as a score of 1 for presence (a score of 2 was for a large amount of discharge or swelling) and zero for absence of mucous discharge or vulvar swelling (normal vulva) as shown in Fig. 1. One animal keeper at each facility observed the animals almost daily when they assumed a recumbent posture in response to body brushing and massages. The detailed degree of score 1 or 2 could not standardized between two females because it was visually determined by one keeper at each facility.

\section{Data analysis}

Data are presented as means \pm SEM. Duration of the estrous cycle was calculated from the first rise in $\mathrm{P}_{4}$ value of one cycle to the rise in the following cycle.

\section{Results}

\section{Blood progesterone profiles}

The profiles of the serum/plasma $\mathrm{P}_{4}$ concentrations of the seven females are shown in Fig. 2. The $\mathrm{P}_{4}$ profiles showed periodic changes; in particular, \#44 (Fig. 2a) and \#86 (Fig. 2f) had consistent cycles throughout the year. In female \#44, copulations were observed just before a rise of serum $\mathrm{P}_{4}$ during 8 cycles (Fig. 2a). The serum $\mathrm{P}_{4}$ concentrations of \#61 remained at the baseline for approximately 5 months beginning in October 2002 (Fig. 2b). From December 24, 2002 to April 30, 2003, this female received medical treatment for systemic dermatitis, emaciation and incidental anemia and hepatopathy. Except for during this period of medical treatment, female \#61 had periodic changes in its serum $\mathrm{P}_{4}$ concentrations, but it did not mate with the male during the study period. Increases in the plasma $\mathrm{P}_{4}$ levels of female \#62 were only observed seven times within a study period of approximately 4.5 years (Fig. $2 \mathrm{~g}$ ). However, the first half of the study period for female \#62 included many months without blood collection, so some cycles may have been missed. One cycle was confirmed for female \#62 at approximately 2 years of age (June-July, 2000), and this female had periodic changes in P4 after approximately 5 years of age (since January 2003). Female \#62 weighed $62.0 \mathrm{~kg}$ when she was introduced into the PRC at approximately 1 year of age, and her body weight reached a plateau of about $300 \mathrm{~kg}$ by approximately $3-4$ years of age 

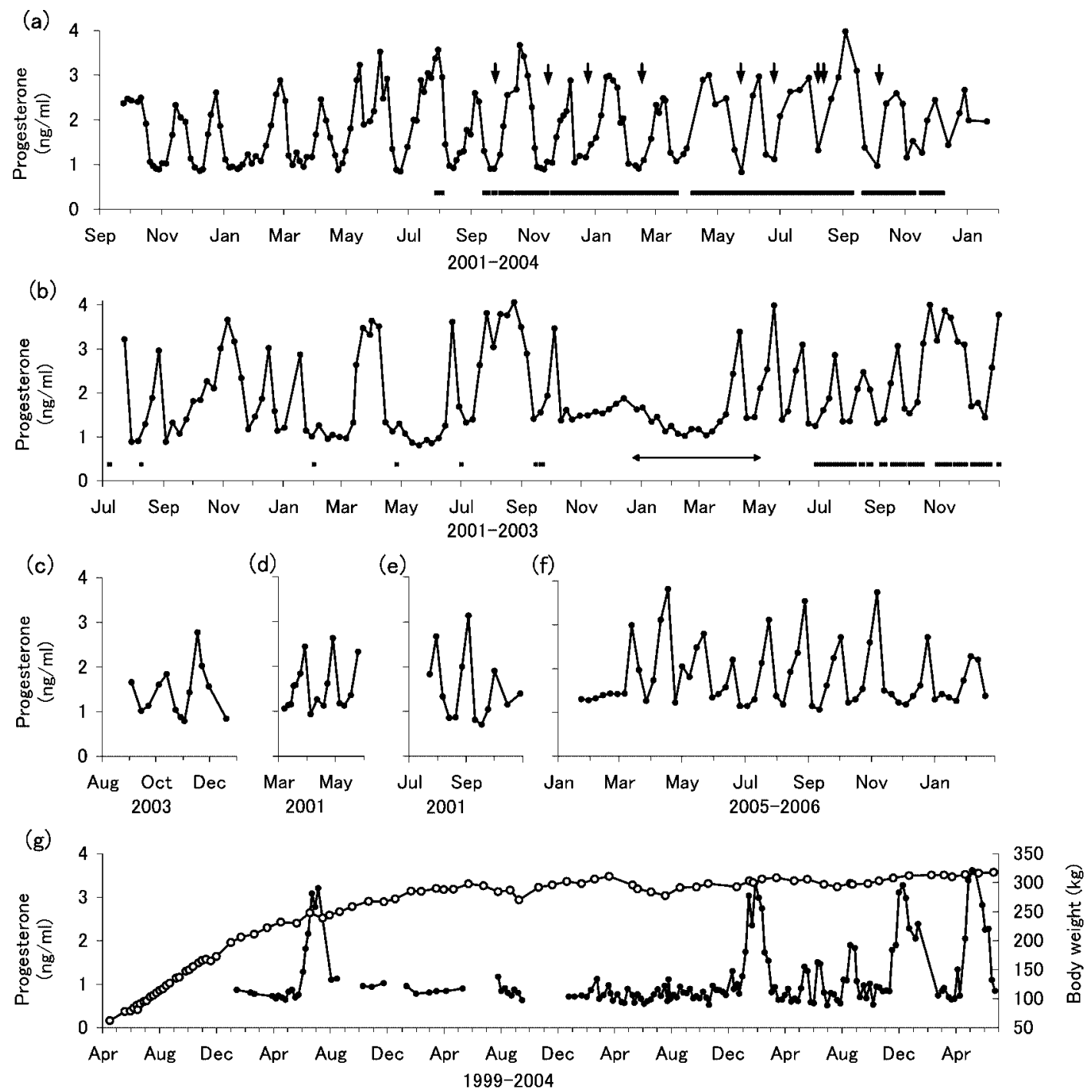

Fig. 2. Profiles of the blood progesterone concentrations of seven female Malayan tapirs, (a) \#44, (b) \#61, (c) \#14, (d) \#56, (e) \#60, (f) \#86 and (g) \#62. Horizontal bars: period of housing together with a male. $\downarrow$ : copulation. $\leftrightarrow$ : period of medical treatment for systemic disease. Graph $(\mathrm{g})$ includes the changes in body weight $(\rightarrow-)$.

(Fig. 2g).

A total of 56 cycles were determined for the seven females by serum/plasma $\mathrm{P}_{4}$ profiles, and the mean cycle length was $43.6 \pm 2.0$ days $(n=56$; range, 21-84 days). The individual distributions of the cycle lengths of the seven females are shown in Fig. 3.

\section{Relationships between vulvar appearance and} progesterone cycle

The relationship between vulvar appearance and serum $\mathrm{P}_{4}$ profile for females \#44 and \#61 is shown in Fig. 4. In most cases, mucous discharge from the vulva and/or vulvar swelling were observed at lower levels (average of $1.24 \pm 0.05 \mathrm{ng} / \mathrm{ml}$ ) of serum $\mathrm{P}_{4}$. However, during some cycles, changes in vulvar appearance were observed at a high $\mathrm{P}_{4}$ concentration (average of $2.70 \pm 0.20 \mathrm{ng} / \mathrm{ml}$ ), in the midst of the luteal phase or within periods in which serum $\mathrm{P}_{4}$ decreased (Fig.4). 


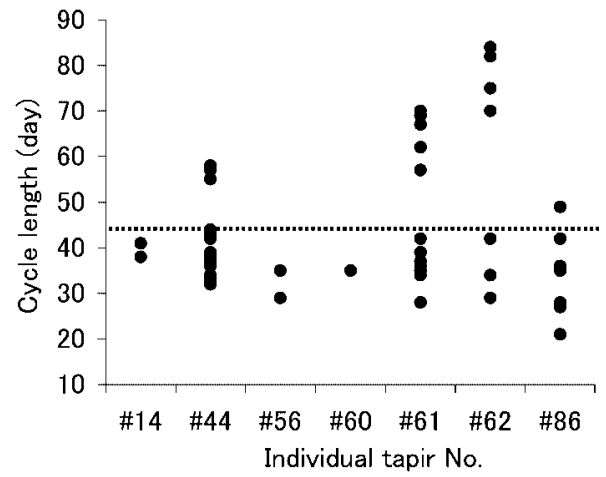

Fig. 3. Individual distributions of cycle lengths of blood progesterone for the seven female Malayan tapirs. The individual cycle length averages $( \pm$ SEM) of females \# 14, \#44, \# 56, \# 60, \# 61, \# 62 and \# 86 were $39.5,44.9 \pm 2.5,32,35,43.2 \pm 3.4,59.4 \pm 8.9$ and $35.0 \pm$ 3.0 days, respectively. Horizontal line indicates the total average of the cycle length.

\section{Discussion}

This study is the first to demonstrate longitudinal profiles of serum/plasma $\mathrm{P}_{4}$ and individual $\mathrm{P}_{4}$ data for a group of Malayan tapirs. Monitoring of serum/plasma $\mathrm{P}_{4}$ was an effective method to determine the estrous cycle of the Malayan tapir, as confirmed by copulations at lower $\mathrm{P}_{4}$ levels. Most of the visual changes in the vulva, such as mucous discharge and vulvar swelling, were also observed in connection with lower $\mathrm{P}_{4}$ levels.

We investigated seven females between 2-23 years of age at the beginning of the study. Except for the data until 4 years of age (January, 2003) in female \#62 and until 2.3 years of age (March, 2005) in female \#86, all other data for the animals revealed constant cyclical changes in serum/ plasma $\mathrm{P}_{4}$. It has been reported that sexual maturity is usually reached in the Malayan tapir at 2-4 years of age or 5 years of age at the latest in captiv-

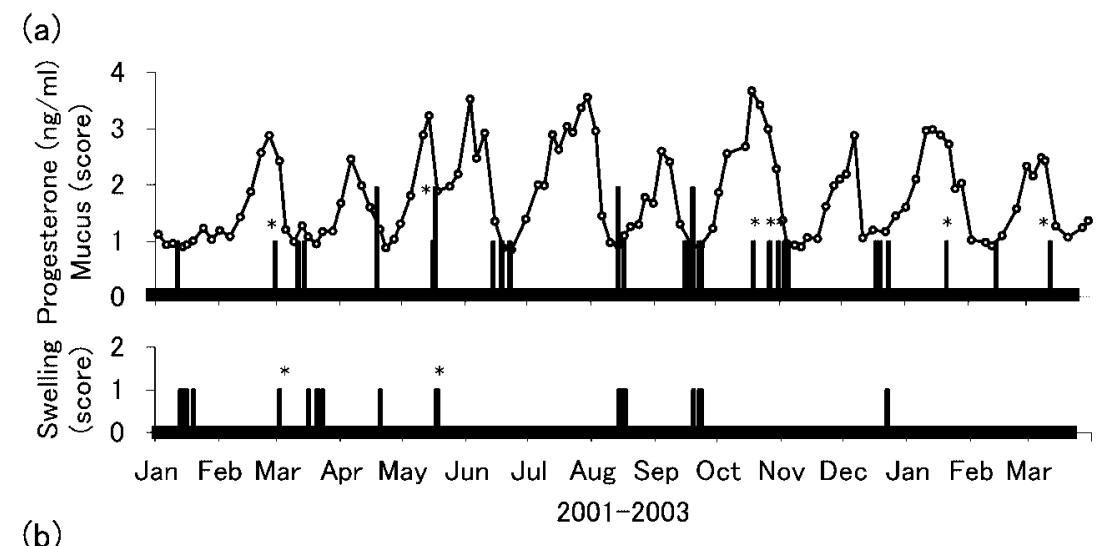

(b)

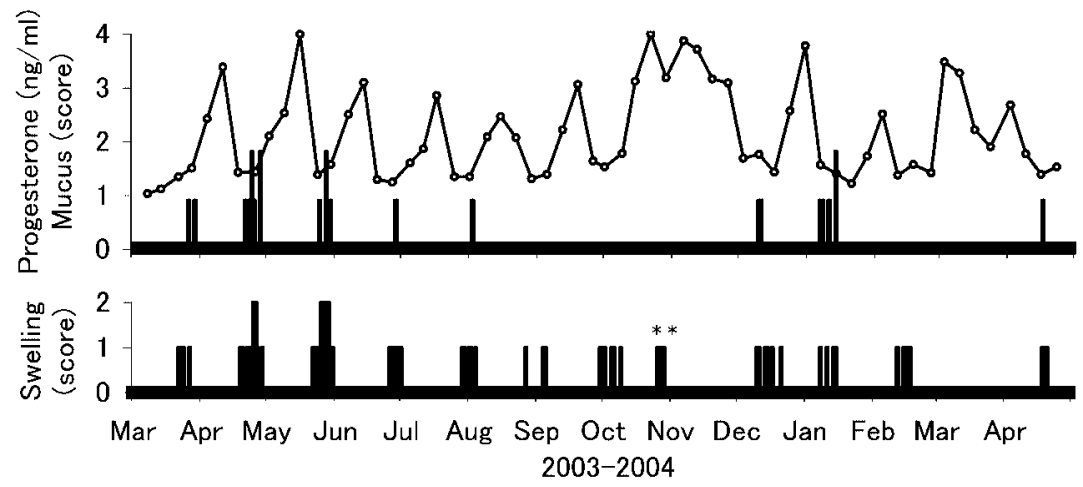

Fig. 4. Relationships among the serum progesterone profiles, mucous discharge from the vulva and vulvar swelling of female Malayan tapirs (a) \#44 and (b) \#61. A vulvar score of one indicates visual presence (score 2 for a large degree) and a score of zero indicates absence (normal vulva) of mucous discharge or swelling. Asterisks indicate the visual changes in the vulva observed at a high $\mathrm{P}_{4}$ concentration. 
ity [1]. The $\mathrm{P}_{4}$ profiles of females \#62 and \#86 may reflect the sexual maturation process.

Most of the estrous cycle lengths of tapir species have been estimated based on the intervals between copulation and/or courtship behaviors. The estrous cycle length of Malayan tapirs has been estimated to be 29.4 [18] or 35 days [19] based on the intervals between copulation and/or courtship behaviors. There are also reports of cycle lengths of between 28-101 days [9] and 2 months [20]. The records of estrous cycles that are 2 or 3 times longer than about one month have been considered to be due to unobserved sexual behaviors or silent estrus. However, the differences in these cycle lengths might not be due to failure to observe behaviors because the long type of estrous cycle (maximum length: 84 days) was also observed in our study. Our report is one of only a few to clarify the blood $\mathrm{P}_{4}$ profiles in order to determine the actual estrous cycle length of the tapir. Only three reports concerning endocrine profiles during the estrous cycles of tapir species were previously available (Baird's, Brazilian and Malayan tapirs). The estrous cycle lengths of Baird's and Brazilian tapirs based on serum/plasma $\mathrm{P}_{4}$ were 30.8 days (mean of two females) [10] and 30.2 and 29.7 days (individual means of two females) [12], respectively. In contrast, the Malayan tapirs in our study had a mean cycle length of 43.6 days (21-84 days; seven tapirs). The length of the estrous cycle based on the plasma $\mathrm{P}_{4}$ profiles of one aged female Malayan tapir has been reported to be 59.25 days (54-63 days; $n=4$ cycles) [13], and this is within range of the cycle length of our study. The estrous cycle lengths of Malayan tapir are longer than those of American tapir species, as described previously (approximately 1 month) $[10,12]$, and vary from approximately 1 month to 3 months. The long estrous cycle, characterized by an extended luteal phase, has been reported in rhino species [21, 22]. Garnier et al. [21] categorized the estrous cycle of the black rhinoceros (Diceros bicornis) as 26.8 (normal type) and 46.7 days (luteal phase extended type) based on fecal progestagen profiles. Patton $e t$ al. [22] classified the estrous cycle of the white rhinoceros (Ceratotherium simum) as 35.4 (normal type) and 65.9 days (luteal phase extended type) based on fecal pregnane profiles. The cause of the extended luteal phase in these rhino species has been presumed to be a reproductive system disease, such as pyometra and endometritis [22, 23], early pregnancy loss $[22,24]$ or ovulation during the luteal phase, which is often observed in mares $[25,26]$. However, our study could not determined whether the long cycle was caused by factors as described in rhino species, whether the normal cycle of Malayan tapir was short (approximately 1 month) or long in length (approximately 2-3 months) or whether the estrous cycle varies greatly in length.

In conclusion, the estrous cycle based on the serum/plasma $\mathrm{P}_{4}$ profiles of Malayan tapirs is 43.6 \pm 2.0 days; however, this mean includes great variation in length, from 21 to 84 days. To promote captive breeding of threatened Malayan tapirs, further investigation is needed to understand the reasons for variations in the cycle length or to determine a reproductive strategy in relation to the variation in cycle length. In the present study, we also showed that visual changes in the vulva can be used as real-time indicators for estimation of a female's estrus status. Visual observation of easy signs, such as vulvar mucus and swelling, would be helpful in captive breeding management of Malayan tapirs.

\section{Acknowledgments}

We gratefully acknowledge Mr. H. Takahashi of the Tama Zoological Park, Tokyo, and Ms. H. Naito of Nagoya Higashiyama Zoo, Nagoya, for assistance with blood collection. This work was supported by the Preservation and Research Center, Yokohama, which provided numerous experimental supplies and regents, and by a Grantin-Aid for JSPS Fellows from the Japan Society for the Promotion of Science (No.18 · 1116). 


\section{References}

1. Lee AR. Management Guidelines for the Welfare of the Zoo Animals Tapirs. London: The Federation of Zoological Gardens of Great Britain and Ireland; 1993.

2. Nowak RM. Tapirs. In: Walker's Mammals of the World Volume II ( $6^{\text {th }}$ ed.). London: The Johns Hopkins University Press; 1999: 1025-1028.

3. Downer CC. Tapirs. In: Macdonald D (ed.), The New Encyclopedia of Mammals. New York: Oxford University Press; 2001: 474-475.

4. IUCN. Tapirus indicus. In: 2006 IUCN Red List of Threatened Species. Available from http:// www.iucnredlist.org/search/details.php/21472/ summ. Downloaded on May 22, 2007.

5. Barongi RA. Husbandry and conservation of tapirs. Int Zoo Yb 1993; 32: 7-15.

6. Todd S, Matola S. Tapir. In: Bell CE (ed.), Encyclopedia of the World's Zoos. Chicago: Fitzroy Dearborn Publishers; 2001: 1204-1209.

7. ISIS. Malayan tapir. In: International Species Information System. Available from https:/ / app.isis.org/ abstracts/Abs76875.asp. Downloaded on May 22, 2007.

8. Kuribayashi K. Internal Studbook of Malayan Tapir, Brazilian Tapir, Baird's Tapir 2004 (1 January 2004-31 December 2004). Tokyo: Japanese Association of Zoological Gardens and Aquarium; 2004.

9. Kuehn G. Tapiridae. In: Fowler ME (ed.), Zoo and Wild Animal Medicine ( $2^{\text {nd }}$ ed.). Philadelphia: Saunders; 1986: 931-934.

10. Brown JL, Citino SB, Shaw J, Miller C. Endocrine profiles during the estrous cycle and pregnancy in the Baird's tapir (Tapirus bairdii). Zoo Biol 1994; 13: 107-117.

11. Janssen DL. Tapiridae. In: Fowler ME (ed.), Zoo and Wild Animal Medicine ( $5^{\text {th }}$ ed.). Missouri: Saunders; 2003: 569-577.

12. Kusuda S, Morikaku K, Koizumi J, Uchida T, Sonoda Y, Kai O, Murata K. Estrous cycle based on the plasma progesterone changes and its seasonality of Brazilian tapirs (Tapirus terrestris) in captivity. Jpn J Zoo Wildl Med 2002; 7: 109-115 (In Japanese).

13. Schaftenaar W, de Boer AM, Glatston AR. Monitoring of the oestrous cycle in a captive Malayan tapir (Tapirus indicus). Vet Rec 2006; 159: 421-422.

14. Topham K, Barrios S. Teaching your tapir to sit, stay, and roll over for blood collection. In: Proceedings American Association of Zoo Veterinarians 2002: 63-64.

15. Kusuda S, Doi O. Reproductive endocrinology of tapirs. Lab Anim Tech Sci 2004; 16: 69-73 (In Japanese).
16. Kusuda $S$, Nagami $H$, Ueda $K$, Doi O, Nishikaku T, Nakagawa D, Takida T, Kurita D, Uemichi K, Fukai M, Kubota H, Ueda K, Ooe T, Okuda K, Kusunoki H. Characterization of the reproductive cycle in female bharals (Pseudois nayaur) based on the changes in serum progesterone concentrations and parturition season. J Vet Med Sci 2006; 68: 847851.

17. Doi O, Takai T, Nakamura T, Tanabe Y. Changes in the pituitary and plasma LH, plasma and follicular progesterone and estradiol, and plasma testosterone and estrone concentrations during the ovulatory cycle of the quail (Coturnix coturnix japonica). Gen Comp Endocrinol 1980; 41: 156-163.

18. Read B. Breeding and management of the Malayan tapir Tapirus indicus at St Louis Zoo. Int Zoo Yb 1986; 24/25: 294-297.

19. Horan A. An outline of tapir management. In: Proceedings of the Symposium of the Association of British Wild Animal Keepers 1983; 7: 24-29.

20. Eisenberg JF, Groves CP, MacKinnon K. Tapirs. In: Parker SP (ed.), Grzimek's Encyclopedia of Mammals. New York: McGraw-Hill Publishing Company; 1990: 598-608.

21. Garnier JN, Holt WV, Watson PF. Non-invasive assessment of oestrous cycles and evaluation of reproductive seasonality in the female wild black rhinoceros (Diceros bicornis minor). Reproduction 2002; 123: 877-889.

22. Patton ML, Swaisgood RR, Czekala NM, White AM, Fetter GA, Montagne JP, Rieches RG, Lance VA. Reproductive cycle length and pregnancy in the southern white rhinoceros (Ceratotherium simum simum) as determined by fecal pregnane analysis and observations of mating behavior. Zoo Biol 1999; 18: 111-127.

23. Radcliffe RW, Czekala NM, Osofsky SA. Combined serial ultrasonography and fecal progestin analysis for reproductive evaluation of the female white rhinoceros (Ceratotherium simum simum): preliminary results. Zoo Biol 1997; 16: 445-456.

24. Roth TL, O'Brien JK, McRae MA, Bellem AC, Romo SJ, Kroll JL, Brown JL. Ultrasound and endocrine evaluation of the ovarian cycle and early pregnancy in the Sumatran rhinoceros, Dicerorhinus sumatrensis. Reproduction 2001; 121: 139-149.

25. Ginther OJ. Diestrous ovulations. In: Reproductive Biology of the Mare Basic and Applied Aspect (2nd ed.). Wisconsin: Equiservices; 1992: 223-224.

26. Stabenfeldt GH, Hughes JP, Evans JW, Neely DP. Spontaneous prolongation of luteal activity in the mare. Equine Vet J 1974; 6: 158-163. 